University of Rhode Island

DigitalCommons@URI

Open Access Master's Theses

1997

\title{
REGIONAL TRANSPORTATION PLANNING IN SOUTHEASTERN CONNECTICUT: AN ASSESSMENT OF THE MAC
}

Heidi L. Samokar

University of Rhode Island

Follow this and additional works at: https://digitalcommons.uri.edu/theses

\section{Recommended Citation}

Samokar, Heidi L., "REGIONAL TRANSPORTATION PLANNING IN SOUTHEASTERN CONNECTICUT: AN ASSESSMENT OF THE MAC" (1997). Open Access Master's Theses. Paper 419.

https://digitalcommons.uri.edu/theses/419

This Thesis is brought to you for free and open access by DigitalCommons@URI. It has been accepted for inclusion in Open Access Master's Theses by an authorized administrator of DigitalCommons@URI. For more information, please contact digitalcommons-group@uri.edu. 


\title{
REGIONAL TRANSPORTATION PLANNING IN SOUTHEASTERN CONNECTICUT: \\ AN ASSESSMENT OF THE MAC
}

\author{
BY
}

HEIDI L. SAMOKAR

\section{A RESEARCH PROJECT SUBMITTED IN PARTIAL FULFILLMENT OF THE REQUIREMENTS FOR THE DEGREE OF MASTER OF COMMUNITY PLANNING}


REGIONAL TRANSPORTATION PLANNING IN SOUTHEASTERN CONNECTICUT: AN ASSESSMENT OF THE MAC

RESEARCH PROJECT

$\mathrm{OF}$

HEIDI L. SAMOKAR
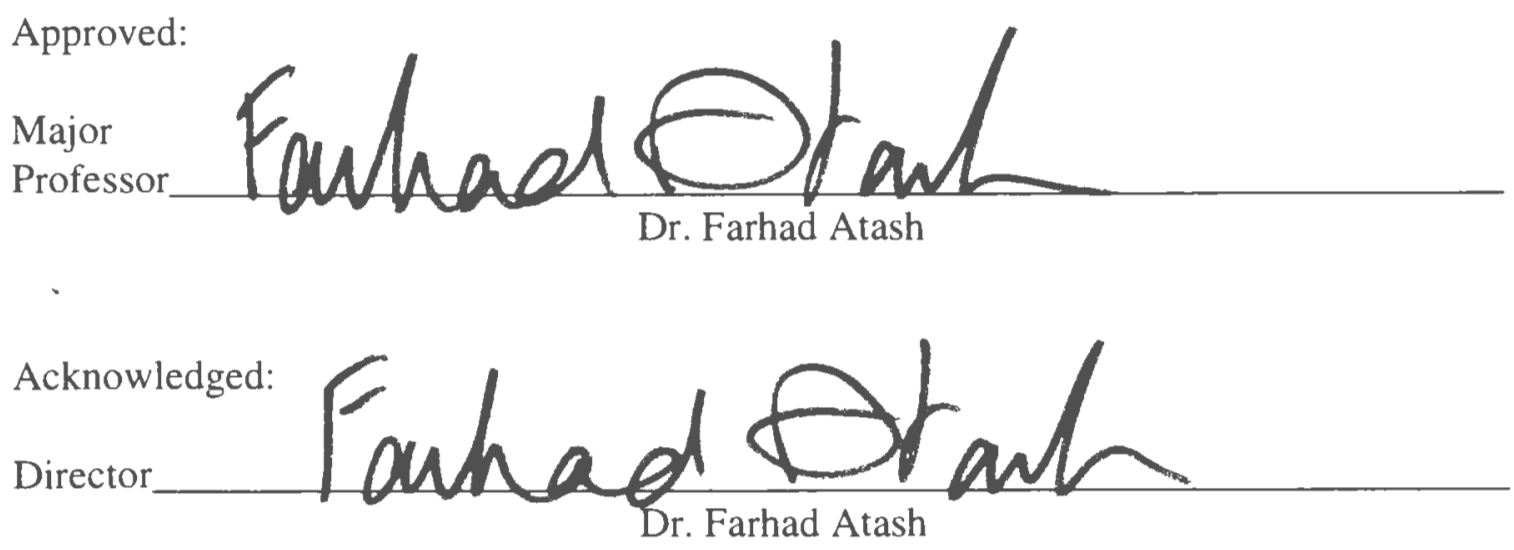


\begin{abstract}
This project analyzed a regional transportation planning process in Southeastern Connecticut. For two years, the Multi-Modal Advisory Committee (known as the MAC) met, under the direction of a transportation consultant and a facilitator, to address the region's traffic congestion. Specifically, their efforts comprised a Major Investment Study (MIS) which is a predecessor to an Environmental Impact Statement (EIS). The MAC's goal was to reach consensus on which transportation alternatives the consultant should further study in the EIS. This group did not reach consensus.

The study looked at two types of factors that may have affected the outcome of the MAC: internal factors and external factors. Internal factors are those which occurred during the process. This entailed an analysis of the groups' common understanding of the problem and objectives, the groups' defined expectations, member's participation, and the role of the project team. The study found that the MAC lacked agreement on the problem at hand and on many aspects of the process. Additionally, the facilitator and project team did not appear to respond accordingly to address these problems.

To assess the effects of external factors, the study analyzed the history of regional cooperation in the study area, regional capacity, power, local politics, and public influence on the process. The findings indicated that a lack of power and funding discouraged the members of the MAC. Also, the group could not separate other problems in the region from the process.
\end{abstract}

The project concludes with recommendations for Southeastern Connecticut and future transportation planning processes. More time should be spent on clarifying the details during the process, such as definitions, evaluation criteria, and the scope of 
solutions to be considered. Despite the failure of the MAC to reach consensus, though, the MAC did offer an opportunity for the region to collaborate on a pressing transportation issue. 


\section{ACKNOWLEDGEMENT}

I would like to thank the readers of my thesis: Dr. Farhad Atash, Dr. Rolf Pendall, and

Jennifer McCann. I appreciate their availability over the summer as I completed this

project. Without their continual and insightful feedback, I would not have learned all that

I did from this study. 


\section{TABLE OF CONTENTS}

ABSTRACT

II

ACKNOWLEDGEMENT

IV

TABLE OF CONTENTS

V

LIST OF TABLES

VII

LIST OF MAPS

VII

LIST OF ACRONYMS

VIII

CHAPTER ONE: INTRODUCTION

Regional PlanNing

2

REgIONAL TRANSPORTATION PLANNING

3

GROUP PROCESS IN PLANNING

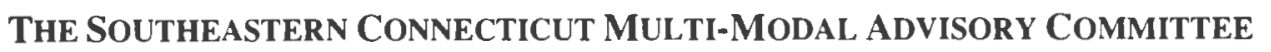

6

OBJECTIVES OF THE STUDY

METHODOLOGY/APPROACH

DATA LIMITATIONS

7

8

ORGANIZATION OF THE STUDY

CHAPTER TWO: BACKGROUND 12

Federal Mandates and Regional Transportation Planning 12 STATEWIDE TRanSPORTation PLanNING IN CONNECTICUT 16 Regional Planning in Connecticut: Council of Governments 17 TransPortation PlanNing In SOUTHEASTERn CONNECTICUT 19

CHAPTER THREE: THE MULTI-MODAL ADVISORY COMMITTEE 2

PURPOSES AND MEMBERSHIP OF THE MAC 26

MAC PROCESS AND OUTCOME 
Understanding OF The Problem and OBJectives

PARTICIPANT'S EXPECTATIONS

MEMBERS' PARTICIPATION

PROJECT TEAM

$\begin{array}{ll}\text { SUMMARY } & 46\end{array}$

CHAPTER FIVE: EXTERNAL FACTORS

HISTORY OF REgIONAL COOPERATION

REgIONAL CAPACITY

POWER

LOCAL POLITICS

PUbLiC RESPONSE

$\begin{array}{ll}\text { SUMMARY } & 58\end{array}$

CHAPTER SIX: CONCLUSION

SUMMARY OF FINDINGS

IMPLICATIONS AND RECOMMENDATIONS FOR SOUTHEASTERN CONNECTICUT

IMPLICATIONS AND RECOMMENDATIONS FOR TRANSPORTATION PLANNING PROCESSES 61

REFERENCES $\quad 64$ 


\section{LIST OF TABLES}

TABLE 3.1: MEMBERS OF THE MAC

\section{LIST OF MAPS}

MAP 2.1： LOCATION OF STUDY AREA 


\section{LIST OF ACRONYMS}

CAAA Clean Air Act Amendments

COG Council of Governments

ConnDOT Connecticut Department of Transportation

EIS Environmental Impact Statement

FHWA Federal Highway Administration

FTA Federal Transit Administration

ISTEA Intermodal Surface Transportation Efficiency Act

MAC Multi-Modal Advisory Committee

MIS Major Investment Study

MPO Metropolitan Planning Organization

NAAQS National Ambient Air Quality Standards

NEPA National Environmental Policy Act

RPA Regional Planning Agency

RPC Regional Planning Commission

RPO Regional Planning Organization

SCCOG Southeastern Connecticut Council of Governments

SCRPA Southeastern Connecticut Regional Planning Agency

SDOT state Department of Transportation

STC State Traffic Commission

USDOT United States Department of Transportation

VHB Vanasse Hangen Brustlin, Inc. 


\section{CHAPTER ONE: INTRODUCTION}

This study will attempt to answer the question: did the Multi-modal Advisory Committee (MAC) transportation planning process in southeastern Connecticut fail? The study will draw on literature on regional planning, transportation planning, and group processes in planning to answer this question. Specifically, it will explore potential reasons for the failure of the MAC to reach consensus by grouping possible causal into internal and external factors. Internal factors will be events, people, and circumstances that occurred during the MAC meetings. External factors will include those factors that affected the MAC, but happened outside of this process. For example, an analysis of the actual process would be an internal factor, while an examination of past regional attempts in the area would be an external factor. These terms are further defined in their respective chapters.

This topic is timely in that transportation planners are faced with a paradigm shift in the way they address problems due to changes in federal policies, such as the Intermodal Surface Transportation Efficiency Act (ISTEA) of 1991 ${ }^{1}$. The ISTEA has been under close scrutiny because it is up for reauthorization in September of 1997. The attempt to solve the transportation issues in southeastern Connecticut reflected this shift in transportation planning. Assessing its problems and successes can help planners in southeastern Connecticut, and elsewhere, with future cooperative planning efforts. Additionally, identifying the influences on this decision-making process may assist policy-makers with other transportation policies and processes.

' Public Law 102-240. 


\section{Regional Planning}

Regional approaches to planning seem to be making a comeback (Wallis 1994, 447). Such approaches can allow areas to address issues that a single jurisdiction can not solve alone, such as transportation issues. However, an area's historical experience with regional approaches can affect the success of current attempts (Florestano and WilsonGentry 1994, 26).

Regional planning efforts face many problems and issues. Many of these issues focus on problems that the regional body, such as a Council of Governments (COG) or a Metropolitan Planning Organization (MPO), must overcome. Problems include:

establishing and maintaining legitimacy, the reluctance of regional bodies to make tough decisions, the need for regional bodies to prove that their efforts are not self-serving, perceptions of ineffectiveness, and the lack of capacity to carry out necessary functions (Wallis 1994). State Departments of Transportation (SDOTs) also face many of these challenges.

Wallis contends that " $[\mathrm{t}] \mathrm{he}$ justification for regionalism has never been stronger..." (1994). However, he also notes that the task of regional efforts will not be easy because many interests exist that benefit from a fragmented approach. Regional planning efforts must address the incorporation of these many interests into the decisionmaking process. 


\section{Regional Transportation Planning}

An overview of regional transportation planning illustrates the paradigm shift that planners are facing: reconciling the concerns and interests of an array of stakeholders.

\section{$\underline{\text { History }}$}

Before the 1960 s, federal transportation policy lacked consistency and comprehensiveness (Levin and Abend 1971,28). In the first half of this century, city planners were not a part of transportation planning: at first they chose not to participate, and then later the transportation experts did not include them (Levin and Abend 1971). In addition, most federal programs authorized money to the state governments with little, if any, money available for planning (Levin and Abend 1971). Even section 701 of the 1954 Housing Act, which provided matching grants to urban and mass transit planning, did not generate regional transportation planning efforts (Levin and Abend 1971, 37).

The Housing Act of 1961 finally included local government along with regional and state governments in transportation policy. However, this legislation still did not tell these levels of government how to coordinate (Levin and Abend 1971, 45). The Highway Act of 1962 was one more small step in the right direction for comprehensive transportation planning. The $3 \mathrm{C}$ process, which involved "continuing, comprehensive, and cooperative" approaches, emerged. Levin and Abend note that by this time it became obvious that coordination, not a lack of funding was impeding effective transportation planning $(1971,46)$.

During the 1970 s more interests became involved in the transportation planning process. Numerous federal regulations formalized the roles of these various interests 
(Meyer 1985, 313). The Clean Air $\mathrm{Act}^{2}$, the National Environmental Policy Act $\left(\mathrm{NEPA}^{3}\right.$, and the Council on Environmental Policy ${ }^{4}$ all affected who is involved in the transportation planning process. This trend and other trends indicated that transportation planning was not purely technical; transportation planning was evolving into a complex, decision-making process. Additionally, MPOs first appeared during this decade.

The 1980s was the decade of decentralization. The federal government took a more flexible approach to transportation issues, allowing the state and local governments to make major transportation decisions. The trade-off for this flexibility was an increasingly complex and costly planning process.

\section{$\underline{\text { ISTEA }}$}

The Intermodal Surface Transportation Efficiency Act (ISTEA) authorized Federal highway and transit funding programs from 1991 to 1997 . This policy decentralizes transportation planning, giving states and localities more control over transportation projects to better meet their needs. The legislation was intended to set a framework for "better planning and management of the Nation's transportation system" (USDOT 1995, 1). USDOT recognizes that because this approach to transportation planning is new, the process is evolutionary in that implementation will take time (USDOT 1995, 1).

ISTEA reflects the need for a shift in how transportation planning is done. Three such changes under ISTEA that are relevant for this project are:

\footnotetext{
242 U.S.C. 7609 , et seq. (as amended in 1990).

${ }^{3} 42$ U.S.C. $4321-4370$ d.

${ }^{4} 40$ CFR $1500-1508$.
} 
- emphasize broader participation including non-traditional participants;

- strengthen the relationship between SDOTs and MPOs; and

- mandate elements that must be a part of the planning process (public involvement, specific factors that must be considered, major investment studies, management systems, financial plans, and relation to State Implementation Plan).

These elements are mandatory for local and state agencies, and for MPOs involved in the transportation planning process (USDOT 1995, 7).

MPOs are responsible for carrying out the transportation planning process with coordination from SDOTs and other relevant agencies. The Federal government does maintain checks and balances on the process though. MPOs have many requirements under ISTEA but are not told how to carry out the process of decision-making. For example, "MPOs should periodically assess their efforts [based on public feedback] and make necessary adjustments" (USDOT 1995, 12). USDOT does not tell MPOs how to balance this feedback. MPOs must "consider" many aspects during the transportation process, but they are not told what "consider" means. The ISTEA clearly spells out the content of what MPOs must consider, but does not spell out how to do the considering. USDOT does offer training for MPOs in conflict resolution and publishes a guide on different techniques of consensus building. However, as of 1995. only three MPOs of 339 requested such help (Gage and McDowell 1995, 153). MPOs need to be able to accomplish these tasks to successfully plan under ISTEA and for regional planning efforts. 


\section{Coordination}

Throughout the history of transportation planning in the United States, many antagonisms existed between the various interests involved. The tension between city planners and engineers became obvious in the 1930s (Levin and Abend 1971, 34). Tensions existed between the federal agencies that oversaw various transportation policies, particularly between the Housing and Home Finance Agency and the Bureau of Public Roads (Levin and Abend 1971, 39). These two federal agencies had had little experience with cooperative transportation planning. Further conflict can be expected within and between various levels of government and between the other involved interests as they increasingly work together to address transportation issues.

\section{Group Process in Planning}

Group processes are a tool that may help transportation planners, such as MPOs, more effectively make decisions. According to Judith Innes "[c]onsensual groups are playing a growing role in planning" $(1992,440)$. Group process has been used for, among other things, land use planning, ad hoc committees, strategic committees, visioning, problem solving, and dispute resolution (Innes 1992, 441). Additionally, regional planning approaches are employing facilitated processes as a means of collaboration (Wallis 1994, 447). Group processes can be important when multiple goals are involved in planning or when the means of reaching the goals is uncertain. Bringing together many interests in a group also allows the combination of many types of knowledge, such as technical knowledge and practical knowledge (Innes 1992, 443). 
Innes also points out certain conditions that must be met for a successful group process. These conditions will be used in this study to analyze the regional transportation planning process that occurred in southeastern Connecticut.

\section{The Southeastern Connecticut Multi-Modal Advisory Committee}

The Multi-modal Advisory Committee (MAC) worked for twenty months, from 1994 to 1996, to develop potential transportation alternatives to alleviate southeastern Connecticut's traffic congestion. This group was comprised of nine municipalities, two Native American tribes, regional groups, state groups, the federal government, and nonprofits groups. A project team, consisting of ConnDOT and the SCCOG, led the group with the help of a hired transportation consultant, Vanasse, Hangen, Brustlin, Inc. (VHB). The goal of the MAC was to arrive at four to six transportation alternatives that the hired consultant would then further analyze in an Environmental Impact Statement (EIS).

The SCCOG is the MPO for this region who, in cooperation with ConnDOT, identified the need for the MAC to provide ConnDOT with alternatives. Specifically, the MAC "was formed to serve as the core of the community outreach effort" with the community being the region (VHB 1995t, 6). The MAC's second purpose was to "...foster regional cooperation by engaging in an intermunicipal and tribal collaborative problem-solving process" (VHB 1995t, 6). The MAC disbanded in May 1996. The group could not reach consensus about which alternatives to advance to the EIS stage, so the decision was left to ConnDOT. The consultant is currently studying ConnDOT's choice of alternatives. 
Southeastern Connecticut will undoubtedly face further regional transportation problems, especially congestion problems, due to the growth in the tourism industry. Identifying the problems behind this regional process may help the region in the future.

\section{Objectives of the Study}

This study has four objectives:

1. Describe background information on transportation planning, the study area, and the MAC process as a basis for the rest of the study;

2. Determine which internal factors affected the outcome of the MAC;

3. Determine which external factors affected the outcome of the MAC; and

4. Based on the findings, address the implications for future undertakings in regional planning in southeastern Connecticut.

\section{Methodology/Approach}

This section explains the methodology used to analyze the MAC process.

Resources included minutes from each MAC meeting, minutes from the public meetings held by the MAC, and public response forms and letters submitted to the project team. Each resource has limitations, which will be discussed shortly.

To understand the internal factors, and many of the external ones, that may have affected the MAC, the study relied upon a content analysis of the MAC's meeting minutes. For each meeting, as series of question were addressed. The questions regarded areas of confusion and disagreement, questions of credibility of other members or outside agencies, concerns over data, negative past experiences, favorable comments about the 
process, and so forth. By categorizing the questions, the comments were pieced together to find trends throughout the MAC process. For example, for the questions about process confusion, the answers from each meeting were compiled onto one sheet to see the evolution of confusion during the process.

Next, member analysis sheets were created for each body that the members represent. For example, each town had one sheet, as did each federal, state, and regional agency. Questions included: what did the members see as the problem at hand, what alternatives did they favor or not favor, what appears to be the agency's or town's overall policy, did the position change during the process, who were the alliances, and who did they conflict with?

Member participation was gauged, again by entity, to see which agencies or towns lacked participation. Attendance alone was not considered participation in the process. If a member spoke at a meeting (as reflected in the minutes) then the agency that member represented received a point. Participation was classified as low, moderate or high.

Public input was compiled by town of residence, using the public meeting minutes, public response forms, and letters submitted to the MAC. Included was a sheet for unknown residence since a large number of comments were not attributed to an individual. The sheets asked what the residents saw as the problem at hand, what alternatives they supported, and what negative and/or positive comments they had about the agencies involved in the study, and the negative comments about the MAC process itself. These results were part of the evaluation of external factors. 


\section{Data Limitations}

As with any source of data, there are limitations. First, most of the analysis relies upon the meeting minutes, which were recorded by the consultants. This could introduce bias into which responses were recorded and how they were framed. However, evidence suggests that the minutes were thorough and accurate. Each meeting was recorded in detail, incorporating positive and negative comments. Even comments questioning the consultants and project team are found in the minutes. Members commended the consultant for providing very thorough minutes over the duration of the MAC.

Additionally, each meeting began by soliciting corrections or clarification of the previous minutes.

Secondly, not every comment could be expected to be reflected in the minutes, nor is every comment attributed to an individual (though most are). Therefore, it is assumed that the comments that were relevant for this project were important enough to be recorded in the minutes. Also, comments during small group work were not provided in the minutes, so the group results were used for those sessions.

Finally, not all of my questions were answerable for all members or towns. For example, very little public comment came from Waterford; therefore, I was not able to come to any conclusions about the public attitudes from its residents. Additionally, public participants were most likely those affected by the proposed transportation alternatives. The public input cannot be assumed to represent the entire public.

In all, these resources were the best available and did provide sufficient data to reach firm conclusions. 


\section{Organization of the Study}

This study is divided into six chapters. Following the introduction, chapters two and three provide background information on transportation planning, the study area, and the MAC. Chapters four and five contain the analysis of internal factors and external factors respectively. The study concludes with chapter six. 


\section{CHAPTER TWO: BACKGROUND}

This chapter reviews transportation planning and the related problems that southeastern Connecticut is facing. The first part provides background information about federal mandates for transportation planning. The second part gives an overview of transportation planning at the state level in Connecticut and at the regional level in southeastern Connecticut. A discussion on background characteristics of the area and some of the conflicts that the planners face in the area is also provided.

\section{Federal Mandates and Regional Transportation Planning}

The Intermodal Surface Transportation Efficiency Act (ISTEA), the Clean Air Act Amendments of 1990 (CAAA), and the National Environmental Policy Act (NEPA) are federal regulations that exert a large influence on the transportation planning process. Each of these acts are relevant for this case study and will be discussed briefly.

\section{ISTEA}

The ISTEA decentralizes transportation planning by giving states and sub-state regions more autonomy in their decision-making. In theory, this policy allows state and local governments to tailor decisions to meet their own needs. ISTEA also mandates broader participation by the public and other relevant agencies, thus involving more interests in the process from the beginning. Additionally, this legislation fosters coordination between the state and local governments, with metropolitan planning organizations (MPOs) being the liaison. 
As discussed in chapter one, MPOs are governor-appointed bodies that carry out transportation planning for a particular region, but operate under federal regulations. MPOs cover populations ranging from 50,000 to 10 million (Gage and McDowell 1995, 135). ISTEA classifies MPOs into small or large MPOs and then further categorizes them as in attainment or non-attainment of the 1990 CAAA. As of 1995, there were 339 MPOs nation-wide (Gage and McDowell 1995, 133). The percentage of these MPOs that are regional councils of governments is 44 percent (Gage and McDowell 1995, 135). Connecticut has ten MPOs.

MPOs were a response to the 1962 Federal-Aid Highway Act which required cooperation between the state DOT and local governments (Pendergast 1994, 40). MPOs' authority changed under ISTEA with more decisions resting with the MPO. For example, MPOs now have the responsibility to allocate funds, create long and short term transportation plans, and involve the public in decision-making. Coordination between the state DOT and MPO is mandatory to work to formulate long range plans, Unified Planning Work Programs and Transportation Improvement Plans (TIPs), and to achieve air quality conformity. Federal staff oversee the progress of MPOs by visiting state and local agencies involved with transportation planning to identify the strengths and weaknesses of their planning process (Lyons 1994, 24).

This expanded responsibility of MPOs comes with problems (Pendergast 1994, 40). First, they lack funding which can be attributed partly to the increase in the number of MPOs without sufficient increases in federal funding. Second, they can experience "political messiness" of many varieties. The relations between the members of the MPO can cause difficulties, as can the relationship between the MPO and the SDOT. SDOTs 
traditionally have been in charge of most major decisions, and may be reluctant to give up some power to the MPOs (Pendergast 1994, 41). Also, the governor can veto the decision of a MPO. Third, they sometimes lack expertise, since transportation planners must now consider a wider range of issues, including economic, social, and environmental effects. Additionally, in many cases the affected agencies have not completely formalized the new planning processes required under ISTEA (Lyons 1994, 24). This is compounded by the fact that federal staff were slow to complete the regulations mandated by ISTEA (Pendergast 1994,40). Lyons alludes to the possibility that the success or failure of MPOs is tied to the past role of the MPO (Lyons 1994). Finally, some transportation planning may occur outside of the MPO's hands, such as when a transit operator makes a major decision. These changes may conflict with an MPO's long-range goals (Lyons 1994, 25).

USDOT offers assistance to MPOs regarding public participation and conflict resolution. Only three of 339 MPOs requested such help as of 1995 (Gage and McDowell 1995, 153). USDOT also publishes guides for various facilitation and decision-making techniques to aid MPOs.

\section{Clean Air Act Amendments of 1990}

The Clean Air Act Amendments of 1990 affect transportation planning since new transportation projects may not violate the National Ambient Air Quality Standards (NAAQS), worsen existing conditions, or interfere with an area's efforts to comply with the standards if not currently meeting air quality standards. The study area is a nonattainment area for both ozone and carbon monoxide. This means that new projects must 
either be proven to improve air quality as compared to a no-build scenario, or a project must be a part of a larger plan that improves the air quality of the area.

\section{NEPA}

NEPA, which sets a national policy to protect the environment, applies to projects that constitute a "major federal action." Regulations established by the Council on Environmental Quality defined the processes behind NEPA, including environmental impact statements (EIS) and the scoping process. Through the EIS process, the lead agency must identify and analyze alternatives based on numerous factors, including environmental impacts. A pre-EIS scoping process can narrow the alternatives that will be studied in the EIS. The FHWA has published procedures for implementing these processes (Weiner 1987, 62).

A major investment study (MIS) may be required during the scoping phase, integrating ISTEA, CAAA, and NEPA regulations, to avoid a duplication of efforts by creating a single comprehensive process rather than three separate processes. USDOT states that the purpose of an MIS is "...to analyze solutions to address substantial transportation problems and present this information to decision-makers" (USDOT 1995, 17). USDOT points out that many factors "should" be considered in an MIS including: the overall effectiveness and cost-effectiveness of alternatives; mobility and accessibility improvements; social, economic, and environmental impacts; and safety. (USDOT 1995, 19). The scope of these factors may require the coordination of numerous experts. The MIS should result in a selection of alternatives that will be further studied in an EIS. 
Federal, state, regional, and local agencies play various roles during an MIS. The FHWA and FTA provide technical assistance and are responsible for NEPA responsibilities, while the role of the state and local agencies are tailored to the specific project (ConnDOT 1995a).

\section{Other Federal Regulations}

Other federal regulations can affect transportation planning by introducing more stakeholders into the process. Such regulations may pertain to: water quality (Clean Water Act of 1977$)^{5}$; wildlife habitat (Endangered Species Act of 1973) ${ }^{6}$; historic preservation (Archaeological and Historic Preservation Act of 1974) ${ }^{7}$; and farmland protection (Farmland Protection Policy Act) ${ }^{8}$ (Haase and Johnson 1996).

\section{Statewide Transportation Planning in Connecticut}

Connecticut was one of the first states to create a state department of transportation. The intention was to combine the duties of planning, development, maintenance, and improvement of the state's transportation networks into one agency (ConnDOT 1995b, 54). For thirty years before ISTEA, ConnDOT was already pro-active in coordinating local and state activities. ConnDOT required coordination between municipalities and the state and worked with regional planning organizations (RPOs) since 1959 (ConnDOT 1995b, 78). In 1974, the department established a Field

\footnotetext{
533 U.S.C. 1341.

${ }^{6} 16$ U.S.C. 1531 et seq.

${ }^{7} 16$ U.S.C. 470.

${ }^{8} 47$ U.S.C. 4201 et seq.
} 
Coordination Unit to act as a liaison between themselves and the RPOs (ConnDOT 1995b, 79).

ConnDOT has established advisory committees and task forces to study transportation issues in other parts of the state. Examples include the Connecticut Public Transportation Commission, the Metro-North Commuter Rail Council, and the Waterbury Branch Train Committee (ConnDOT 1995a, Appendix G). Very similar to the process that this project is based on was the advisory committee that ConnDOT established to study alternatives for the Q Bridge in New Haven (ConnDOT 1995b). This group came to consensus on six alternatives for further study. Therefore the MAC process was not a new idea for ConnDOT.

\section{Regional Planning in Connecticut: Council of Governments}

Connecticut legally allows three types of regional planning organizations (RPOs): regional planning agencies (RPA), councils of elected officials (COE), and councils of governments $(\mathrm{COG})^{9}$. In general, an RPO's main purpose is to carry out planning activities in the particular region by assisting individual municipalities and coordinating intermunicipal issues. The State Office of Policy and Management defines the boundaries of such regions. Municipalities become members of an RPO when they amend their local ordinances accordingly. Since the RPO for the study area is a COG, the rest of this section focuses on the structure and powers of a COG.

The structure of a COG is established by state legislation and the bylaws of each COG. State law requires that the chief elected official of each member municipality is

\footnotetext{
${ }^{9}$ Connecticut General Statutes, Chapter 127, 8-31a - 8-37.
} 
the representative on the COG, with each representative having one vote. ${ }^{10}$ Federally recognized Native American tribes may participate in the COG, but state law does not allow them to have a vote. If a COG loses its membership to a level below 40 percent of the region, the COG is downgraded to a council of elected officials.

Overall, a COG's scope includes any matter that a municipality is concerned with, from education, to waste disposal, to economic development. According to Connecticut General Statutes, COGs have the power to consider regional matters, promote economic development, promote cooperation, make recommendations, serve as a forum, develop policies, initiate and coordinate actions, and to carry out regional planning. However, the COG's bylaws require that planning matters are handled exclusively by the regional planning commission (RPC), which is a division of the COG. This branch is comprised of representatives from each member's planning commission. Similar to the COG, each member of the RPC has one vote on issues.

Traditionally COGs have faced many difficulties in accomplishing their goals, with some similar problems to those of MPOs. Additional troubles include: suspicions of self-serving interests, perceptions of ineffectiveness, and the perception of being an impediment to regional decision-making (Wallis 1994). COGs may also suffer from fragmentation due to varying interests of member municipalities.

\footnotetext{
${ }^{10}$ Connecticut General Statutes, Chapter 50, 4 - 124k.
} 


\section{Transportation Planning in Southeastern Connecticut}

Overview of Region and Study Area

The southeastern Connecticut region, as mentioned, covers twenty-one municipalities or boroughs and two federally recognized and sovereign native American nations, the Mashantucket Pequot Indians and the Mohegan Indians. Map 1 illustrates the area. In $1990,240,432$ resided in the region (SCCOG 8,1996 ). This population grew by twenty-four percent from 1960 to 1990 , while the amount of developed land jumped by 245 percent during the same period (SCCOG 7, 1996). Currently, the region's most prominent land use for developed land is residential (SCCOG 7, 1996).

Nine municipalities in this region comprise the study area: Ledyard, Preston, North Stonington, Stonington, New London, Groton, Norwich, Montville, and Waterford (Mystic is a part of Groton). The SCCOG divides the study area into urban, suburban, and rural towns as follows (refer to Map 2):

Urban towns: Groton, New London, Norwich Suburban towns: Ledyard, Montville, Preston, Stonington, Waterford Rural town: North Stonington

Almost all of the region's major employers (places employing at least fifty) are located in the study area (SCCOG 14, 1996). Currently, the Mashantucket Pequot Tribal Nation is the region's largest employer (SCCOG 5, 1996).

\section{$\underline{\text { Southeastern Connecticut Council of Governments }}$}

The Southeastern Connecticut Council of Governments (SCCOG) represents twenty-one municipalities and boroughs. This region is "region 13" in the state. SCCOG 
Map 1: Location of Study Area

Connecticut

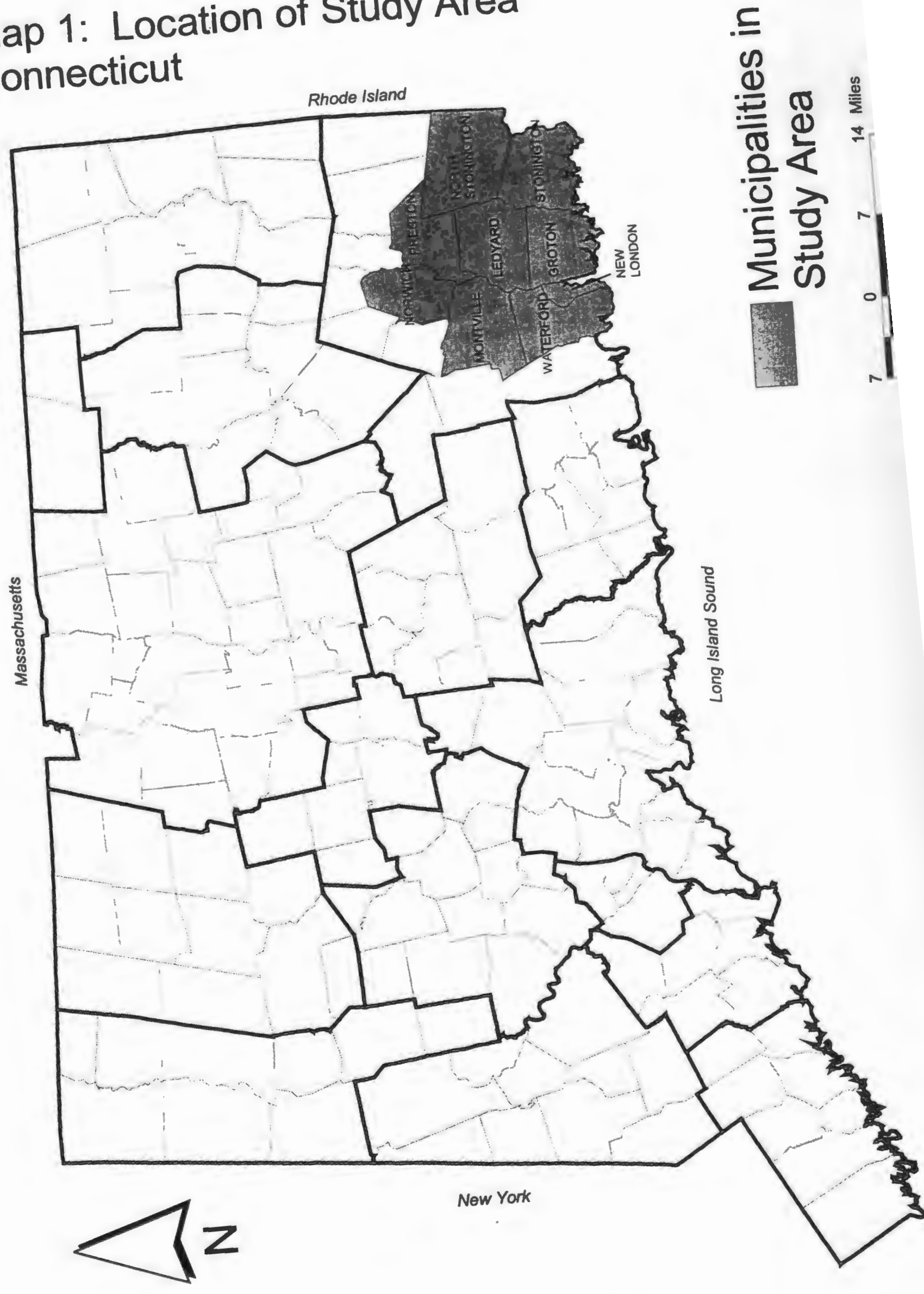




\section{Map 2: Study Area and Transportation Corridors}
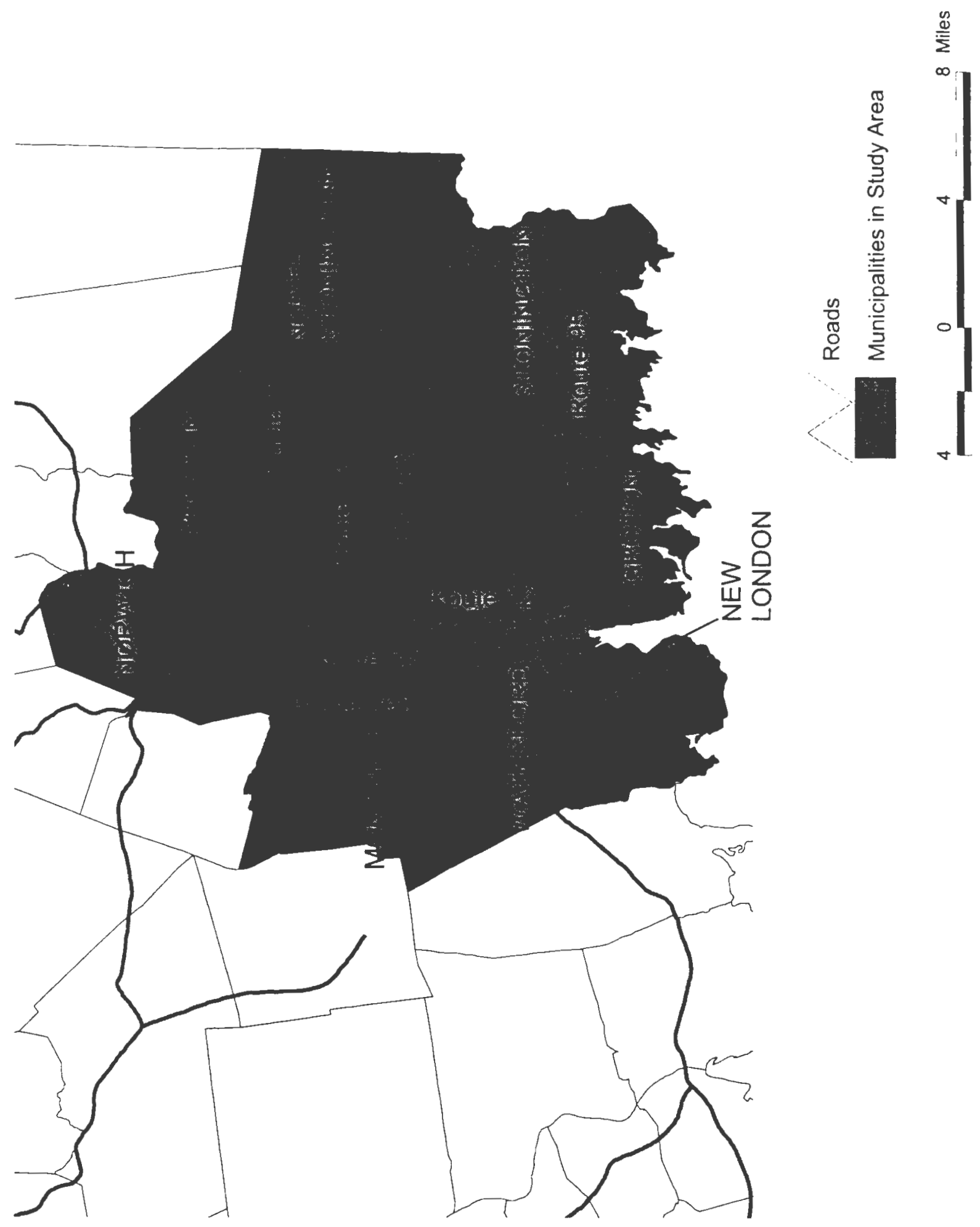

Source: MAGIC, University of Connecticut Libraries 
has a staff of an executive director, assistant director, planners, and a secretary. A different regional body preceded the SCCOG.

The Southeastern Connecticut Regional Planning Agency (SCRPA) was organized in 1961, and by 1967 southeastem Connecticut saw its first regional plan. During this time, the group was responsible for reviewing and commenting on local and state actions, and creating plans and reports. However, the regional body did not have power to implement the plan (SCRPA 1976). In 1973, the Governor appointed SCRPA as the MPO for that region, thus giving the agency an emphasis on transportation.

The SCRPA was reorganized into the Southeastern Connecticut Council of Governments (SCCOG) in 1993, and remained the MPO for this region. This agency reorganized into a COG because its members believed the change would enhance public sector involvement, allow stronger cooperation, and link planning and implementation (SCRPA 1992, 2). In addition to transportation planning, SCCOG provides governmental services such as those mentioned in the previous section on COGs.

Conflict and controversy surrounding the powers of a regional body in this region are not new. A recent proposal by the RPC to strengthen the scope of its own power has been met with resistance by the COG. Specifically the proposal was to give the RPC the right to review projects of a certain size, with the RPCs decision binding on the affected town unless overruled by the town's planning board. The RPC was also seeking to change state law to allow itself a larger role in the regional planning process. Both proposals were opposed by the COG. The first proposal was considered a threat to "[t]he state's long history of local control..." (Arellano 1997, B1). One local politician noted other reasons for opposition including "[it] would take away local control, add a layer of 
bureaucracy and increase development costs for businesses" (Arellano 1997, B1). Also, the COG was founded under an agreement that the group never would have veto power over another town's decision. The editors of the New London Day feel part of this opposition is due to the competition that exists between the municipalities in the region (The New London Day 1997, A8). They go on to note "...what a fiction regional planning really is in southeastern Connecticut and other areas in the state."

Finally, SCRPA itself recognized the regional obstacles any planning body faces:

"With its strong, some might say obsessive, tradition of home rule, Connecticut has always posed a challenge to the development of programs to provide services on a regional basis" (SCRPA 1993, 4).

SCRPA did note some of the more successful regional operations in the area though. These include SouthEastern Connecticut Transit, Southeastern Connecticut Water Authority, and the Southeastern Connecticut Tourism District (SCRPA 1993, 4).

\section{Background: Southeastern Connecticut's Current Transportation Issues}

During the $1990 \mathrm{~s}$, defense-related jobs began to decrease, while the tourism industry increased, due to the opening of Foxwoods Resort Casino in Ledyard in 1992 and the Mohegan Sun in 1996, in Montville (VHB 1997, I-1). This increase in tourism has greatly affected the transportation systems of the region and is perceived to threaten the rural character that defines much of the area. As the executive director of the Mystic Chamber of Commerce stated, "[w]e have confusion and congestion on our roads, threatening to destroy our quality of life and economic opportunity as well" (Peter 1997, $\mathrm{Cl})$. 
An estimated twenty-five million people visit the region each year (Peter 1997, C4). On a peak day, Foxwoods hosts up to 50,000 visitors (VHB 1997, I-1). As can be expected, traffic has increased drastically, creating congestion and safety concerns (VHB 1997, I-1). These traffic concerns affect all levels of roads in the study area: two interstate systems, state routes, and local roads.

Certain corridors, particularly Route 2 , have a history of summertime congestion from beach traffic. But current problems are worse and/or more frequent than past problems. For example, Route 2 sees two to five times more traffic now than in 1980 . By 2015, this number is expected to double again and most roads will exceed their design capacity (VHB 1997, II-36). The area is experiencing problems with large vehicles, such as buses and trucks, using secondary routes; roughly ninety buses per day deliver patrons to Foxwoods (VHB 1995d). Additionally, access management becomes an issue with the current and expected growth in these high traffic corridors (VHB 1997, II-36).

The region can expect to continue to grow with more tourist attractions planned by numerous parties. These include numerous large hotels in Norwich and Montville, further development of Foxwoods Resort and the Mohegan Sun, possible expansion of the Groton-New London Airport, the expansion of the Mystic Marinelife Aquarium and Mystic Seaport, and OceanQuest (VHB 1997, II-25). Due to these future expectations, the current demand must be reduced for these corridors and/or the existing roadway capacities must be improved to meet demand (VHB 1997, II-38). ConnDOT and both tribes have undertaken some roadway improvements, while more are planned for the immediate future. Finally, the future plans of both tribes create much uncertainty over the 
location and extent of growth in the region, especially since the tribes collectively own land in all of the nine municipalities in the study area.

ConnDOT conducted an informal study of possible improvements for the stretch of Route 2 through Preston, Ledyard, and North Stonington. An ad hoc advisory group consisting of these three towns, the Mashantucket tribe, and ConnDOT oversaw this study. As a result, ConnDOT proposed a highway bypass plan and a rail plan to address the problems. However, public opinion revealed the controversy surrounding these proposals at the public meetings held by ConnDOT. As a response to these concerns, SCCOG asked ConnDOT to hire a consultant to conduct a formal study of the larger region: nine municipalities and three transportation corridors (Garrett 1997). ConnDOT halted the previous study and turned that information over to SCCOG to be used in this newly initiated study. SCCOG and ConnDOT agreed to use a committee of stakeholders, known as the MAC, to carry out the MIS phase of this project. This committee will be described in chapter three. 


\section{CHAPTER THREE: THE MULTI-MODAL ADVISORY COMMITTEE}

To begin this regional transportation planning project ConnDOT hired Vanasse Hangen Brustlin, Inc. (VHB), a consultant, to conduct a Major Investment Study, and then prepare an Environmental Impact Statement. As part of the MIS, ConnDOT decided to establish a representative committee to oversee the study and to participate in the transportation decisions. Thus, the Multi-Modal Advisory Committee, locally known as the MAC, was formed in 1994.

This chapter explains what the MAC was, what it did, and the outcome.

\section{Purposes and Membership of the MAC}

The MAC was formed for two key purposes. First, the MAC was to evaluate transportation alternatives that they would formulate during the process. These alternatives would improve corridor traffic conditions and access in the study area, with a ten to fifteen year implementation period (VHB 1997, I-2). The second purpose of the MAC was " to foster regional cooperation by engaging in an intermunicipal and tribal collaborative problem-solving process" (VHB 1997, I-2). The members of the MAC would assist the consultant by serving as the core of the community outreach effort. The intended product of the MAC would be four to six transportation alternatives that would be further evaluated in an EIS. The consultant would compile a report based on the work of the MAC, which would comprise the MIS.

Members of the MAC represented the region from the Norwich/Montville area to the south, and east to the Rhode Island state line, covering nine municipalities. The chief 
elected of ficial from each municipality plus one appointee served as members. In most cases, the planner was the appointee. Also, regional, state, and federal agencies, and the two Native American Indian Tribes were represented on the MAC. Table 1 lists the entities represented on the MAC. In total there were forty members and a project team that included the consultant, a facilitator, and ConnDOT. ConnDOT played a dual role as a member of the MAC and as a part of the project team.

Table 3.1. Members of the MAC.

City of Groton

Town of Groton

Town of Ledyard

Town of Montville

Town of Stonington

Town of North Stonington

City of New London

City of Norwich

Town of Preston

Town of Waterford

SouthEast Area Transit (SEAT)

Mohegan Tribe and Council

Mashantucket Pequot Tribe

Dept. of Planning

Bureau of Indian Affairs

The MAC determined that the state and federal agency representatives and

SCCOG staff would be members as well as provide input on matters within their

jurisdiction and expertise (VHB 1997, I-2). Membership changed during the MAC

process due to local election results in November 1995 as is explained in chapter four.

\section{MAC Process and Outcome}

The MAC met biweekly on average for twenty-one months, from September 1994

to May 1996. During these meetings, which were led by the facilitator, the members 
outlined the direction of the study, presented data, sought input, defined the transportation problems of the region, developed alternatives, and evaluated the alternatives. This section highlights the steps that the MAC went through.

\section{Step 1: Establishing MAC protocol}

Before beginning work on the problem at hand, the members had to decide on the process itself. Specifically, the MAC had to decide how the public would be involved, the ground-rules for meetings, decision-making criteria, and other rules. The project team assembled these decisions into the MAC Protocol, to which all members were to adhere.

The MAC defined the roles of the members, the project team, and the facilitator.

The members were to:

- seek support from constituencies:

- "participate in a meaningful way to further the interests and concerns of their constituencies;"

- provide information about the MAC to their constituencies;

- "come to meetings with the freedom to invent and explore options;" and

- provide ConnDOT and SCCOG with alternatives (VHB 1994e).

The project team was to serve two roles: facilitation and technical services. The facilitator would chair meetings, help establish agendas, identify areas of agreement and disagreement, remain non-partisan, and facilitate the exchange of information and consensus building (VHB 1994e).

The MAC decided upon the role of the public during the meetings. Members of the public would be allowed to speak if time were available or if the MAC agreed to hear the comments. Written testimony would also be allowed but "at the discretion of the facilitator [the comments] will be presented to the MAC" (VHB 1994e). These rules for 
participation were for the MAC meetings only; they did not apply to the numerous public information meetings, where they allowed more input from the public.

Finally, the MAC defined consensus to mean “...decisions that each member can live with." (MAC 1994e). Additionally, the protocol stated that "MAC members agree to support the MAC agreement in that they will not seek additional alternatives" (MAC 1994e).

Step 2: Data collection and discussion to identify existing problems

The first six months of the process revolved around collecting and discussing information about existing conditions in the study area. The MAC worked in small and large groups, made presentations to one another, and took a bus tour of the area to learn about the region's transportation problems. Toward the end of this stage, the MAC held two public meetings to display this information and to receive input.

\section{Step 3: Future projections}

This phase spanned a few months. The MAC members provided the land use visions for their municipalities, while the consultant prepared projections of future traffic conditions.

A MAC member from each municipality presented the future land use vision for his/her city or town to the group as did the planners from Foxwoods Casino. The land use visions were to provide the following information to the MAC: planned roadway improvements, proposed development of both casinos and resort areas, other major developments in the region, and the secondary growth that may accompany development 
(VHB 1997, II-25). From the state level, the Office of Policy and Management presented the State Plan of Conservation and Development to the MAC. Their results highlighted nodes of development in the regions that may become more intensely developed in the future, as well as which areas may remain relatively undeveloped (VHB 1995d).

The consultant prepared projections on future traffic volumes using a transportation model and data from ConnDOT and the towns which had the necessary data. The results indicated which roads would be over capacity due to increasing traffic volumes by 2015 (VHB 1995g).

This combination of existing and future transportation and land use conditions helped the members define the need for the MAC process. It also would be used as a baseline from which to compare the effects of proposed transportation alternatives.

Step 4: Preliminary identification of transportation alternatives

The MAC brainstorming efforts resulted in over one hundred ideas for transportation improvements (alternatives) for the region. These potential solutions to the region's traffic problems ranged from new highways, to railways, to bicycle amenities, to a tunnel. The members sorted the ideas into four lists, with the " $\mathrm{A}$ " list containing those alternatives that would be further evaluated since they appeared to be within the scope of the study. After presenting thirty seven alternatives at the next round of public meetings, the MAC incorporated some of the public's new ideas with their alternatives.

Step 5: Contract with the MAC 
The consultant prepared the "Contract with the MAC" to outline the study objectives to serve as the framework for the next level of evaluation of the alternatives. The MAC reviewed and amended this contract. The criteria specified that the alternatives must:

1. meet future demand (safety, operations and congestion, mobility, the number of vehicles entering the region, and traffic volumes on secondary roads);

2. preserve the quality of life (scenic/visual resources, residential environment, and cultural resources);

3. minimize environmental impacts (wetlands, water resources, air quality, noise quality, and undisturbed habitats and open space);

4. maximize cost effectiveness; and

5. address economic and land use concerns (effective land use, jobs and economic development) (VHB 1996, IV-78).

\section{Step 6: First level screening of transportation alternatives}

The MAC further eliminated alternatives and then combined the remainder into nine packages, each including minor improvements, such as improving intersections, along with a major proposal, such as building a busway. The nine alternatives included: a "no-build" as required by NEPA, four roadway bypass alternatives, and four transit alternatives. This stage lasted roughly seven months. Again, public meetings allowed input from residents of the region.

\section{Step 7: Second level screening of transportation alternatives}

The nine alternatives, were subjected to a second screening by both the consultant and the MAC, with the hope of selecting four to six to go to the EIS stage. The MAC evaluated the alternatives in more detail, specifically regarding engineering, 
transportation, and environmental concerns. This analysis was presented at a public meeting.

Step 8: Attempts at selection of final transportation alternatives

The consultant presented its "technical recommendations" of four alternatives to the MAC (VHB 1997, IV-176): the "no build" alternative, two bypass alternatives, and one transit option. The MAC was not able to reach consensus on which package of alternatives it wanted to advance. They did reach consensus on a few points, with one point being that mass transit should be advanced to the EIS stage. Members were informed from the beginning that if they could not reach agreement, the decision would be left up to ConnDOT. Thus, in 1996 ConnDOT selected six alternatives to study in an EIS: the "no build", two bypass options, and three transit options (VHB 1997, IV-181). This stage signified the end of the MAC.

\section{Step 9: The Environmental Impact Statement of selected transportation alternatives}

The consultant is currently working on the EIS for the six alternatives selected by ConnDOT. This step has a twenty-four month time frame for completion.

\section{Summary of Findings}

The twenty-one month process had many positive results including an extensive public outreach effort, the provision of local and regional information to the consultant, and extensive cooperation between the members. However, because the MAC did not reach its goal of consensus on transportation alternatives to be further studied, the process 
may be called a failure. The following chapters will identify the internal and external factors that may have impeded the MAC from reaching consensus. 


\section{CHAPTER FOUR: INTERNAL FACTORS}

This chapter analyzes the MAC process by looking at the internal factors that may have impeded the group from reaching consensus, and thus failing to achieve its overall goal. For this project, internal factors will be defined as those actions and interactions which occurred within the MAC meetings and the group process itself. The MAC worked on two levels: content (the transportation issue) and process. This section is concerned with the latter. The meetings are treated as a closed activity, as if there were no outside influences; chapter five will look at the external factors. Some factors do not fit neatly into either internal or external factors, while others may belong under both. For the purpose of this analysis, each is classified as one or the other.

Specifically, this chapter addresses the four ingredients for a successful group process (Center for Conflict Resolution 1978; ConnDOT 1995a; Innes 1992; Pindur and Yacus 1996). These are:

- common understanding of the problem and objectives;

- defined expectations:

- members' participation; and

- a responsible project team.

The analysis of each factor begins with a discussion of its importance followed by an examination of how that factor appeared in the MAC.

\section{Understanding of the Problem and Objectives}

Sharing common objectives and meanings can foster cooperation, which in turn helps the members feel more committed and motivated, and enables trust (Center for 
Conflict Resolution 1978, 34). Differences in definitions will "undoubtedly hinder collaboration among and within agencies" (Emerson 1996, 21). Therefore, identifying the group's common problem and objectives and agreeing on the various meanings are critical steps to be undertaken at the beginning of the process. A group should be able to identify the its overall goal and how it will reach that goal. The facilitator must be sure that the members of the group are trying to solve the same problem.

Basic definitions should be established in the process. Often the meanings of terms that the process focuses on seems obvious. However, sometimes such definitions are not clear. Innes discusses an example in Florida where disagreement over the word "sprawl" led the committee to take the time to develop a definition for it $(1992,444)$. Also, participants should understand the meaning of decision-making terms. When a group is working towards consensus on an issue, each member must understand the meaning of "consensus." When participants must make decisions based on "good reasoning", they must first agree on the definition of "good reasoning" (Innes 1996). Is "good reasoning" based on technical merit, social issues, or politics, for example? The way in which a member defines terms may reflect his or her agency's or town's values and norms.

During the MAC process, the group was often confused or in disagreement over the study's objectives and the meanings of phrases that the process depended upon. Specifically, problems arose over the definition of the problem, why alternatives should be selected, and who they were planning for. 


\section{Definition of the Problem and Objectives}

The results indicate that the group was not able to clearly define the problem initially nor did all of the members agree with the definition of the problem. The MAC spent many meetings assessing current traffic problems and projecting future traffic in the area. Areas of agreement emerged, as did many of disagreement. During the first few months of the MAC, the members worked in groups to discuss the current problems. Each of the three groups framed the region's problems differently. Group 1 identified problems along the region's backroads and the resulting threat to the residential character of the area. Group 2 took a local approach by focusing on the home town of Foxwoods, Ledyard. Group 3 addressed the entire study area with an overriding concern for safety (VHB 1994f). These different approaches show that the scope of the problem was not consistent among members (that is, local versus regional problems). However, with the help of the facilitator, the group came to agreement on the problem: traffic on back roads was affecting quality of life. As the process continued, this agreement seemed to be forgotten by the members.

After seeing the future traffic projections prepared by the consultant, many members of the MAC expressed concern. In at least six meetings, some members expressed concern that the numbers were too high; and others thought them to be too low. If indeed the consultants future traffic projections were too high, then maybe there was not a problem to be addressed. If the numbers were too low, then the problem may be much worse than the participants believed. At the end of the process, one member felt that none of the nine alternatives would solve what he saw as a problem: the traffic along one particular route (VHB 1996a). By the end of the MAC, members from North 
Stonington did not feel that there was any problem and therefore no need for any solutions--it saw construction of any alternative as the problem (VHB 1996e).

Some did not see traffic as a problem, but rather as an economic opportunity (VHB 1994e). The problem to them was that the drivers were not stopping to spend money. This point of view did not come from the host towns of Preston, Ledyard, Stonington, and North Stonington (towns that would be directly impacted by any transportation improvements).

The MAC appeared to disagree as to whether there really was a problem, and if so, its magnitude. Although there seemed to be agreement at the beginning of the process, such agreement was unclear by the last few meetings. Much of this disagreement came from the host towns.

\section{$\underline{\text { Alternative Selection and Consensus }}$}

During the first MAC meetings the project team explained that the goal of the MAC would be to reach consensus on a range of alternatives to be studied in an EIS. The MAC agreed upon a definition of consensus: decisions that each member can live with (VHB 1994e). The facilitator further noted that the group must agree on the package of alternatives, not each individual one. Despite this definition, the issue of consensus was never clear, nor were the criteria for selecting and then evaluating alternatives.

During brainstorming activities, conflict emerged over the scope of the proposed alternatives. This conflict was not resolved, and remained for the duration of the MAC. For example, some members were unclear whether they should propose short or long term solutions (VHB 1995a). Others felt strongly one way or the other, either preferring 
immediate solutions or long term solutions (VHB 1994b). This issue appeared again the following November (VHB 1995n). Then came the question of how specific the alternatives should be. Should the solutions state exactly where the improvements will be, or should the alternatives be more general (VHB 1995g)? All of the planners felt a need for more comprehensive alternatives that would include a land use component (VHB 1995j).

Once the group developed a list of over one hundred solutions, they established their own criteria for evaluating alternatives. These criteria, listed in chapter three, were spelled out in "Contract with the MAC" in July 1995. By the end of the MAC, these criteria did not appear to be agreed upon: there was disagreement over what exactly the above stated criteria meant; some members were using other criteria; and others did not understand what it meant to forward an alternative. Even in the second to last meeting, a planner asked for clarification on the criteria for forwarding alternatives (VHB 1996d).

Conflict between the members and the consultant became evident during a discussion on the varying meanings of subjective terms such as "reasonable" (VHB 1996e). The project team explained to the members that NEPA requires that the range of forwarded alternatives include "reasonable modes and alignments" (VHB 1996e). This resulted in discussion and disagreement over what "reasonable" means to members. The consultant stated that reasonable is based on quantifiable data rather than how people feel about an alternative (VHB 1996e). Two members disagreed, arguing that quality of life is an integral part of this process, as the MAC had earlier decided. One member then questioned why the MAC even existed (VHB 1996e)? Members from all four host towns wondered the same. 
Furthermore, the members could not agree whether unrealistic or unsupported alternatives should be forwarded. For example, one planner felt that alternatives that would not receive an environmental permit should be screened out now, during the MIS (VHB 1996d). In other words, he felt that the MAC should not forward alternatives that they did not want to see built. Other members, including the EPA, felt that the EIS would take care of that level of analysis. They believed the MAC could forward alternatives that they do not support to the EIS and have the EIS show that those alternatives are not feasible. Neither the facilitator nor the members ever resolved this issue.

In the midst of this confusion and disagreement, the time came for the MAC to reach consensus. Numerous times, the facilitator and the members themselves asked other members to state which alternatives they want to be forwarded, rather than which ones they did not want built (VHB 1996d and 1996e). The member analysis showed that by the end, the majority of the MAC favored forwarding a balance of alternatives, recognizing that they did not necessarily have to support its actual construction to see it forwarded to the EIS. However, the host towns did not agree.

After much discussion of who did not want what, the members could not even agree if they had reached consensus. One member felt they had reached consensus; another felt they reached consensus on some alternatives; and others, including the project team, felt they did not reach consensus (VHB 1996e). This process led to personal attacks, with two members claiming that the consultant and/or SCCOG engaged in the "arm-twisting" of other members to lend their support for roadway alternatives (VHB 1996e). 


\section{Who Were They Planning For?}

The MAC studied a variety of transportation alternatives. One question that came up many times, was who were these alternatives for? Current tourists? New tourists? Residents? Commuters? Casino patrons? At least two times members asked this question (VHB 1995n and 1996d). Many other comments alluded to the fact that the MAC did not seem to be on the same wavelength on this matter. A member from New London discussed the possibility of connecting alternatives to the ferry terminal so that tourists from Long Island could take advantage of the ferries. Other members questioned this strategy since it would bring in more people to the area. Most members focused on providing ways to get casino patrons to and from the casinos with the least impacts. However, toward the end of the meeting, one member from a host town announced that he will not cater to casino patrons (VHB 1996d).

\section{Participant's Expectations}

When members have different expectations than the facilitator, or from other members, problems can result. Members of the MAC may have had varying expectations regarding the role of the $\mathrm{MAC}$ during the process and in the future, the regional scope expected of all members, and the level of detail in an MIS. As noted earlier, the MAC's self evaluation showed concern over the lack of clarity of the future of the process.

Members were concerned with the role of the MAC during the twenty-month study, the role of the MAC during the later EIS stage, and the role of the MAC after the EIS is completed. First came confusion over the role of the MAC versus other agencies, 
such as ConnDOT's State Traffic Commission (STC) (VHB 1996c). The project team clarified that the STC, which addresses developments that generate large amounts of traffic, addresses short term concerns while the MAC would focus on long term solutions. However, throughout the process, some members stressed the need for immediate shortterm solutions to alleviate congestion due to the casino (VHB 1994b). Therefore, their expectations of the type of solutions the MAC should propose did not match the expectations of the project team, or of the other MAC members. At one point, the project team reminded the MAC that all issues will not be solved by the MAC (VHB 1996c).

Most of the members and the project team had expectations about other members of the MAC. They expected members to look at the whole region, not just local issues. One planner vented such frustrations (VHB 1995n). She noted at another meeting that some town will have to bear impacts for the good of the region (VHB 1995e), while other towns felt that it was unfair for a town to tolerate impacts (VHB 1996d). During the last two meetings, the facilitator and other members expressed concern that many members were only protecting their own interests and not thinking of the region as a whole (VHB 1996d).

Other expectations cropped up that may not have been realistic. For example, one elected official stated that the tribes can solve all of the traffic problems along a particular corridor (VHB 1995g). A planner felt that the reality of the group's expectations to locate satellite parking in the region. She questioned if any town would be willing to place parking lots within their borders (VHB 1996b). In other words, some members expected the alternatives to be constrained by political realities, while others did not seem to feel the same way. 
Funding expectations and concerns dominated the last two meetings, as the MAC tried to reach consensus. The "Contract with the MAC" did establish cost efficiency as a criteria for the evaluation of alternatives. The consultant also felt that only cost feasible alternatives should be forwarded to the EIS. However, the MAC never clearly understood what fiscal constraint meant. One member felt this issue had been resolved early on, but other members seemed to struggle with whether the money had to be available to fund the alternatives at the start of construction, whether alternatives could be built (and thus funded) in stages, or if they should not worry about funding until the EIS stage (VHB 1995n). Many members felt that all of the alternatives were unrealistic because of their seemingly prohibitive costs, but felt there was the possibility of getting funding from the tribes. What exactly did feasible mean? This issue was not resolved.

Finally, many members of the MAC had unrealistic expectations of the MIS process itself. The project team explained the processes at the beginning and the end of the study. However, numerous times throughout the twenty months, members felt that the information provided and studied at the MIS stage was not adequate enough to base decisions on. Members felt that air quality should be addressed in the MIS (VHB 19951); agreed to include air quality in the report. Another member felt decisions could not be made without financial information. which would not be analyzed until the EIS (VHB 1996a). The project team had to reiterate that not all information is looked at in the MIS stage (VHB 1996a). In the last meeting, a member of the project team stated that the purpose of an MIS is not to ask the communities what they want, but to see whether the technical numbers warrant further study of an alternative (VHB 1996e). In other words, 
even the project team had different expectations that the criteria originally set forth in the "Contract with the MAC."

\section{Members' Participation}

Participation, for this study, means more than just showing up at the meetings; it requires contributing to the process itself. This may include sharing information, asking and answering questions, stating opinions, and even arguing. For this study, participation of the town or agency was measured rather than an individual's level of participation, unless the town/agency was represented by only one person.

Maximum participation and diverse representation in the meetings is integral to a successful group process. Many absences or a lack of participation is an issue that must concern a facilitator (Center for Conflict Resolution 1978). Having a variety of interests involved in the process from the beginning may legitimize the decisions that result from the process (USDOT, FHWA and FTA 1994, G-1). For example, if one affected town contributed minimally during the process, that town could claim that the final decision ignored that particular town's needs and concerns. On a similar note, each participating town or agency can be viewed as a resource. The group is better equipped to make decisions when all of these resources are available to the group. If a member does not participate until the end of the process, the group may find that this late-comer member would have been an important resource for the group.

Finally, participation may give each member a sense of ownership of the problem at hand, and thus ownership of the process. When members see that the project team 
responds to their concerns, they may feel that their voice will make a difference in the outcome of the process.

The project team designed the MAC for broad representation from Federal, State, regional, and local interests. However, participation was not equal among these interests and was non-existent for some interest groups. Of twenty-four meetings, seven federal agencies, three state agencies, and one Native American Tribe had minimal participation (they spoke at fewer than five meetings). Collectively, these non-participators comprised forty percent $(40 \%)$ of the agencies/towns represented on the MAC. Only six agencies/towns participated in more than three-quarters of the meetings. This group of six included the SCCOG and the RPC, three of the four host towns, and New London.

The members themselves were concerned about a lack of participation. As part of the process, the MAC underwent a self-evaluation ten months into the process (VHB $1995 \mathrm{~g})$. The group noted the lack of involvement by the chief elected officials and by the Native American Tribes. Though the group did not name those chief elected officials, analysis shows that those officials from Groton, Norwich, Montville, and Ledyard barely participated. Other times throughout the twenty months, members again mentioned the lack of participation by elected officials. The mayors and first selectmen did not deny this accusation; one noted that her busy schedule often conflicted with the meeting times (VHB 1995j). Regarding the tribes, the Mashantuckets participated in just under half of the meetings, while the Mohegans barely participated. The MAC did not appear to be concerned over the lack of participation by numerous state and federal agencies, as there was no mention of it in the minutes. 
Over a year after the process began, the project team was confused over who was or was not a member, so they allotted time at the beginning of a meeting to clarify this issue (VHB 1995n). Local elections, which resulted in membership changes for four towns, caused part of the confusion. In addition, the project team was unsure of who the designated members from both tribes were due to their minimal appearances. Also, the MAC received a new member one month before the end of the process (VHB 1996c).

On a positive note, many members of the MAC appeared committed to the process, as gauged by their presence and by comments during the meetings. The MAC did provide a forum for participating members to air their concerns and work toward solving a regional problem.

\section{Project Team}

A facilitator guides a group; if she (in this case) goes astray, so will the group. She must make sure the group agrees on aspects of the process and must address disagreements that arise. Without adequate facilitation the process can become unglued. The role of the other members of the project team is less critical for this study, therefore this section focuses on the facilitator.

The role of the project team, including both the facilitator and consultant, appeared successful at the surface level. The facilitator followed many of the rules outlined by the Center for Conflict Resolution for successful facilitation. She appeared neutral throughout, pointed out areas of agreement and disagreement, summarized major points, kept the discussion focused on the topic at hand, and provided a variety of formats for group work. All process decisions were given to the MAC, such as the dates of 
meetings, when to take breaks, the formulation of the alternatives, etc. The protocol outlined the role of the facilitator, assuring that the group understood this role. The self evaluation noted the success of facilitation.

However, after completing the analysis on common meanings, participant's expectations, and participation it is evident that the facilitator did not guide the MAC as effectively as she could have. First, the facilitator did not ensure that a common definition of the problem was reached by the group. Secondly, the project team did not clearly set forth what was expected of the MAC after the process. Finally, when the project team realized that numerous interests were not participating or even attending the meetings, further efforts should have been made to incorporate them. However, since this analysis only reflects the content of the minutes, a clear conclusion cannot be reached as to whether the project team contacted non-participants.

The project team, including ConnDOT, provided the MAC with technical data and analyses needed to make decisions. Innes points out the need for such help with technical data in group processes $(1992,441)$. Perhaps most importantly, the team responded accordingly to data concerns by the MAC. For example, often times a member would question a piece of data or an assumption. The project team would address the concerns, usually by the next meeting.

\section{Summary}

The overall process should not be deemed a failure based on the problems highlighted in this chapter. Innes notes that the group processes she studied had limited success. For example, she studied eight groups in California that tackled planning issues. 
These groups achieved only some consensus, their resulting products were not necessarily used, and not all disputes during the processes were solved $(1992,451)$. However, the participants did work together.

This analysis of internal factors that may have influenced the MAC process appears to show that many issues were unclear or contentious throughout the process. These issues included definitions, identification of the problem and common objectives, a full understanding of the MIS process and how the MAC fits into this process. Other internal factors may have been of concern also. However, not every factor was measurable with the data available. The factors that were measured, however, seem to have played a role in the problems the MAC faced. 


\section{CHAPTER FIVE: EXTERNAL FACTORS}

This chapter analyzes external factors, which are those issues that occurred outside or before the MAC, that may have affected the decisions of the group members and the MAC's outcome. The external factors are categorized into five groups based on a literature review: the history of regional cooperation, regional capacity, power, local politics, and public influence (Pendergast 1994; Pindur and Yacus 1996; Florestano and Wilson-Gentry 1994; Wallis 1994). These factors do not necessarily occur as discrete and identifiable issues, but may be interwoven with other external factors or with internal factors. But for ease of discussion they are addressed categorically. Each section describes the factor and then discusses how it influenced the MAC.

\section{History of Regional Cooperation}

The regional history of an area can play a large role in the decision-making process (Florestano and Wilson-Gentry 1994, 26). If past regional efforts have failed, participants may feel that again, their input will not make a difference. For similar reasons, the past relations and reputations of the various agencies involved in the process are also important. Particular attention is paid to ConnDOT's reputation since they are the agency that leads transportation decisions in the state. History also includes the attitudes of the municipalities and agencies regarding transportation issues and regional cooperation. For example, a town may have a history of rejecting or resenting outside "help" to solve its problems.

According to the meeting minutes, many members of the MAC did not have a positive outlook on past regional efforts and transportation projects. One planner 
highlighted the lack of regional efforts in the study region when she noted that the people in the region say "it's never been done before" as an excuse not to work together (VHB 1995j). Three areas of concern arose during the process: members having a negative impression about past efforts and projects, a history of strong local control, and traditional resistance to transit options statewide and in the region.

Comments from members reflected a lack of faith in regional efforts and past transportation projects. Members blamed the state and federal governments for not providing sufficient funding (VHB 1995n). It became clear that the members' perceptions of other transportation projects were not favorable either as they discussed their frustrations over past transportation projects and initiatives. In general, members felt that the state did not allow or consider regional or local input for past projects. For example, one town mentioned how the STC did not incorporate the town's concerns into a previous project (VHB 1994e). Another member noted that private developers seem to have an easier time dealing with the STC (VHB 1996d). Also, many members were frustrated with the past piecemeal approaches to transportation planning due to regional fragmentation (VHB 1996c). One planner noted the lack of regional support for more comprehensive issues such as access management (VHB 1995e).

As discussed in chapter two, the local press highlighted the resistance to cooperation in the area due to a history of strong home rule tendencies. Many of the comments by MAC members illustrated this preference for local control over development. A member from a host town voiced concern that in the past, land in the town had been taken out of the tax base without compensation (VHB 1995n). He did not feel this was a fair practice. Another member brought in his town's three-hundred-year 
history of not developing (VHB 1995d). One member summarized preferences for local over regional control by reminding the other members that the Connecticut state legislature had recently turned down a proposal to give regional planning agencies more power (VHB 1995j).

Finally, the MAC showed disbelief that transit would be viable based on a past lack of support both regionally and at the state level. Overall, members appeared to see a historical lack of support from ConnDOT and the governor for transit alternatives. For example, the state has a bad reputation for cutting money for commuter rail, or not even allotting transit money for towns east of the Connecticut River (VHB 1995a). Others noted the historical lack of federal funding support for mass transit projects, despite proposals from SCCOG (VHB 1995n). Additionally, the member from SCCOG stated mass transit options have never received the support from the towns (VHB 1995a). This issue is further discussed in the section on regional capacity.

How did these negative views affect the MAC process? Some members saw the MAC as an opportunity to change past trends (VHB 1996e). Specifically, the process was allowing the region to have more input than traditionally (VHB 1996d). Others made statements to the effect that the region's past tainted the process: why should they believe that the current attempt is different past ones? The host towns indicated that local sacrifices for the benefit of the region are unreasonable and unfair. However, a member from Groton refuted this attitude by showing that such sacrifices have occurred in the past. She noted that Groton, home to numerous large employers, had taken the brunt of impacts such as new roads to support these large employers. That was a regional issue in 
which one town sacrificed. Now the towns with the casinos are in that same boat (VHB 1996a).

\section{Regional Capacity}

Because the SCCOG, as the MPO, is the regional transportation leader for the study area, its capacity to provide technical and administrative support to achieve regional initiatives was critical. Most importantly, would the SCCOG have the funding to implement the final product of the study? Members needed to believe that their time would be well spent.

Questions over SCCOG's leadership capacity did not arise during the MAC. The analysis looked for negative comments about the SCCOG in past projects, or concerns over their technical or leadership capacities. However, the MAC spent much of its time discussing funding. This leads to the conclusion that funding, rather than technical and leadership capacities, was of primary concern.

Funding surfaced throughout the entire MAC process; the current funding situation and the region's past financial capacity became evident through the dialogue in the meetings. Discussion centered on the fact that the region receives only twelve million dollars a year for transportation projects, whereas the least expensive alternative (excluding the "no build") would cost over \$103 million dollars (VHB 1995n). Funding was a larger issue for transit options since they are more expensive to construct. Members recognized the lack of federal and state support for transit alternatives since traditionally, most funding went to highways (VHB 1995a). ConnDOT reminded the 
MAC that there is not a blank check waiting to be spent on an alternative; the MAC should not expect easy financing for the outcome (VHB 1996b).

Funding issues have created problems in other case examples, such as the transportation steering committee in a Hampton Roads study in Virginia in 1994. This group felt hopeless due to funding uncertainties. They believed they were creating a "financially constrained vision" (Pindur and Yacus 1996, 139). Such feelings may have been present during the MAC. This lack of money caused some MAC members to feel that the process had been useless, while others felt that funding would be found if an alternative had enough support (VHB 1995n). This amounted to a schism between those who felt only fundable alternatives should be forwarded to the EIS, and those who felt ideal solutions should be forwarded in the hope that funding would be found. Some members even concluded that all regional solutions, in general, were too expensive to support (VHB 1995m).

\section{Power}

Power, as an external factor, may influence a group process in a variety of forms. It may mean the power struggles that occur between decision makers at various levels of government. Inherent conflicts between institutions may result in power struggles. Planners and politicians may fundamentally disagree on issues and policies, as may politicians and transportation planners. The lead agencies of a project may fundamentally disagree. For example, state DOTs may be set in the traditional mode of highways only policy, while the MPO may feel otherwise (Gage and McDowell 1995, 148). All members are supposed to be on equal ground during the meetings, but outside the MAC 
certain entities have power over the ultimate decisions and the implementation of those decisions. Additionally, decision-makers may feel threatened by private entities who can make major decisions without public input. These private entities may include private transportation providers, or in this case, sovereign tribal nations.

In terms of the MAC, three sources of power loomed over the process:

ConnDOT, tribal power, and the power of the numerous federal and state resource agencies such as the U.S. Environmental Protection Agency, the Connecticut Department of Environmental Protection, and the U.S. Army Corps of Engineers. These concerns often detracted from the MAC's sense of legitimacy because they felt they would have no control after the MAC ended. More than once, members questioned why they were even there if other agencies had the ultimate control over the region's future. They also questioned whether their decisions mattered when the tribes are sovereign nations that do not have to abide by state or local regulations.

Members felt that ConnDOT did have the upper hand in the end. Some expressed concern that the transit alternatives would not be taken seriously by ConnDOT outside of the MAC (VHB 1994b). Others felt "coerced" into supporting road alternatives because ConnDOT's current projects in the area were road projects and because roadway solutions are cheapest (VHB 1995a). One member even suspected ConnDOT of "armtwisting" to convince members to support roadway alternatives (VHB 1996e). This accusation proved to be unfounded. Members also realized they cannot control the STC's decisions either (VHB 1996c). Additionally, ConnDOT had many other roadway improvements programmed for the area already, of which the MAC had to work with in the "no build" scenario. These added limits to what the MAC could propose. 
Frustrations over the lack of control over tribal development aired during at least one meeting (VHB 1995g). Members felt that the lack of state and town control over the tribes created a more difficult situation to work with. For example, the project team reminded the MAC that they do not have control over certain elements, such as the number of parking spaces the tribes provide (VHB 1996c). In other words, the towns, state, and federal agencies would not be able to control tribal development. Frustrations may have been compounded by the lack of participation by the tribes, and their unwillingness to answer questions at times (VHB 1995b). The tribes held financial power over the MAC also; they had the money to fund improvements. Both tribes had improved local roadways as related to their development plans, and the Mashantuckets offered three times during the process to help fund the alternatives proposed by the MAC (VHB 1995n).

Toward the end of the MAC, the project team and resource agencies explained that it is their institutional policy to evaluate certain alternatives regardless of whether the MAC selects them (VHB 1995n). For example, a member from the Army Corps of Engineers pointed out that the Corps will issue a permit only if the selected alternative is the least environmentally damaging (VHB 1996e). At this point, a member from one town questioned why the MAC existed if the final decision laid elsewhere. Also, the "Contract with the MAC" cited a concern for social issues, but the resource agencies based their concerns on environmental criteria. Again, in the second to last meeting, the resource agencies reiterated this reality, with another member again asking why the MAC was needed (VHB 1996d). 


\section{Local Politics}

Norris defines local politics as "political events, conditions, and circumstances unique to a local area at a given time" (Norris 1992, 158). Politicians, planners, and the public are all players in local politics. For example, the individual economies of the region may be in conflict, thus affecting local political policies and decisions. Some towns see growth as a threat, while others see it as an economic opportunity. Also, elections may change local politics and thus the policies of the MAC members. These policies then become part of the MAC process through its members.

This study gauged the policies of the towns through the member analysis. Positions and comments of the members were cumulated under the town they represent to see if there was a common goal or policy for each member town. In general, the host towns' policy was that of no new roads. These four towns are less developed and not seemingly growth-oriented. Montville, New London, Waterford, Groton, and Norwich, however, are more developed towns/cities and seem to view growth as an economic opportunity. These five towns also tended to favor a balanced approach to the alternatives. This comparison of the host and nonhost towns leads to the conclusion that there were conflicting policies over economic growth and preservation that affected the outcome of the MAC.

The decisions and events that occurred before or outside of the MAC seem to further support these local policies. Before the MAC, residents opposed a Route $2 \mathrm{~A}$ bypass (VHB 1994f). Three of the host towns held referenda during the MAC opposing road improvements and either supporting the "no build" alternative or rail options. In 
addition, the Ledyard town council passed a resolution endorsing the elimination of a bypass through Ledyard (VHB 1996d). Each host town would not support the forwarding of an alternative if the residents had rejected it. The MAC questioned how these local actions would affect their decisions. Both the project team and the SCCOG responded that the MAC is not bound by these outside decisions (VHB 1995n). One planner acknowledged that the MAC also takes place outside of the meetings: at council meetings, in people's houses, etc. (VHB 1996e). In other words, the MAC really is not a closed process, void of local decisions and opinions.

Regional solutions seemed implausible, since many members could think only of their own town. The facilitator and various members pointed out a few times that each town cannot just protect its own interests (VHB 1996d). Many members could not, or perhaps did not want to, separate local politics from the regional goals.

\section{Public Response}

Public input is an external influence since members of the public did not have a formal role in the MAC. However, the MAC received substantial feedback from area residents that may have influenced them directly in their decisions, or at least stimulated discussion. Public involvement introduces many more stakeholders with varying interests into the process. The members must reconcile these often antagonistic views with their own. Elected officials, in particular, may feel directly responsible for addressing their constituents' needs.

The MAC was very concerned with public input. Members spent large parts of many meetings discussing and devising public input strategies. Many were also 
concerned with their credibility to the public. For example, some members were afraid to show the public their original list of over one hundred brainstormed alternatives since some were unrealistic (VHB 1995e). Another member felt the MAC's credibility would be questioned if expensive alternatives were presented to the public (VHB 19950). Members were aware, though, that the input they were receiving was mostly from those members of the public that were most affected by the problem at hand.

The study looked at public opinion on the transportation problem and the alternatives, the public's feelings toward the MAC, and their stated opinions on regional issues. Overall, the public did not view themselves as part of the transportation problem or as a user group for the future alternatives. Many felt that the MAC was catering to the tribes. Others thought that there was no problem that needed to be solved and therefore no need for the MAC. However, many others did see a problem, but no one clear public sentiment over the alternatives was evident. Many of the public comments and concerns seemed similar to the questions that the MAC struggled with: who were they planning for and is there even a problem?

The public from the host towns voiced more negative comments than from the other towns, especially regarding the tribes and ConnDOT. Residents from North Stonington believed that the tribe was influencing the decision-makers and the MAC. They felt that the tribes should deal with the traffic problems and therefore did not support the existence of the MAC.

As mentioned, there was not clear public sentiment except perhaps in the host towns. The host towns used that public sentiment to support their stand for or against certain alternatives. They felt the pressure from the local public to solve the problems at 
hand (VHB 1995a). Other members realized that the public will never accept any of the alternatives because someone will always be affected (VHB 1996d).

\section{Summary}

This chapter shows that the MAC was not able to escape outside pressures and realities. They recognized the limited power they might have in the final selection and implementation of any alternative. Feelings of "why should we even bother" appeared, especially at the end when trying to reach consensus. Others could not set aside their local interests for the benefit of the region, or perhaps did not recognize that benefits must come at a cost to someone. However, as seen, some members did view this collaboration as an opportunity to overcome those external hurdles discussed in this chapter--i.e., let the region's voice be heard. 


\section{CHAPTER SIX: CONCLUSION}

The problems highlighted in this study are not new problems; transportation planners have encountered these same obstacles in other cases. The purpose of this study was to see which problems affected the outcome of the MAC. This chapter summarizes the findings and discusses implications and recommendations for regional planning in southeastern Connecticut and transportation planning processes in general.

\section{Summary of Findings}

The analysis of internal factors suggests reasons why the MAC could not reach consensus on which transportation alternatives to study in an EIS: the lack of agreement on the problem and the process. The lack of an appropriate response by the facilitator and project team probably further impeded the MAC from reaching consensus. The analysis of internal factors, however, highlighted some successes of the MAC. The MAC provided an opportunity for planners, politicians, tribal representatives, and state agencies to discuss the traffic condition in the region. Whether or not the participants agreed on the problem, solutions, or process, they did collaborate and share information. The MAC also fulfilled one of its objectives of providing ConnDOT and the public with information about the region.

The analysis also identified external factors that may have influenced the outcome of the MAC. Particularly, a lack of funding for transportation projects and a lack of knowledge and input on further tribal developments appeared to have created a "why 
bother?" attitude. This feeling seems to have led many members to feel that the MAC would not be able to influence transportation decisions.

Overall, this analysis showed that the problems confronted by the MAC were not just about traffic congestion. Problems regarding funding, tribal development, growth policies, for example, all affected the participants and their decisions in the MAC. Additionally, the external factors clearly influenced the internal factors. Members incorporated local politics, ConnDOT's history, and other perceptions into the process.

\section{Implications and Recommendationș for Southeastern Connecticut}

The stakeholders in the region share many problems that ideally they should address collectively. Regional problem solving in Southeastern Connecticut is not a simple process, as the MAC illustrated; parties must confront and overcome complicated issues in such endeavors. The towns and cities will continue to face uncertainty over the type and enormity of future tribal development and tourists will continue to bring more cars into the area. At the same time, transportation planning at the regional, state, and federal level will continue to emphasize more inclusive methods of decision-making. Although this study showed what went wrong with this problem-solving process, it demonstrates the benefits such efforts can have in regions facing growth. Benefits included increased public awareness, increased dialogue between the participants, and the provision of information to ConnDOT. In brief, although this process had its faults, it could be a very useful technique for further regional collaboration.

This study generated the following recommendations for the study area: 
- Many differences between the municipalities must be confronted. The growth policies of the municipalities in the area will continue to be different, with some trying to attract more tourism and others resisting the accompanying growth. These policies conflict. The leaders should work together to identify how these policies can complement one another rather than conflict. Until this fundamental difference is addressed, further problem solving processes could have results similar to that of the MAC.

- The SCCOG staff should take an active role in promoting more group problemsolving processes. This MIS process may have been a foreign concept to the MAC members. Perhaps using problem-solving processes at a smaller scale could help the decision-makers in the region become more accepting of such techniques.

\section{Implications and Recommendations for Transportation Planning Processes}

MISs are only three years old, therefore it is unrealistic to expect the process to be perfected, or even smooth. Using one example, in this case the MAC, to make conclusions about the whole MIS concept would not be appropriate. However, this analysis does identify problems that could be addressed for other processes. Most of these problems are also recognized by transportation experts, but are not necessarily accounted for in MIS processes yet.

The following recommendations pertain to the process itself. Although they are based on the MAC, most could apply to other group processes in regional planning and transportation planning. 
Most of these recommendations show that regional transportation planning is a very detailed and lengthy process requiring the expertise of many individuals and groups. To involve a group that are not experts, requires much time for educating. Granted, taking this extra time would lengthen any process, but a longer and successful process is more favorable than a short and inadequate one.

This project looked at the surface of process problems. Further research on the history of regional efforts in the area, and a closer look at other projects of ConnDOT would help lend more insight to the impediments that affected the MAC process. Such an analysis could clarify if the responsibility lied with ConnDOT, the consultant, or the facilitator.

Transportation policy seems to be on the right track regarding its increasing inclusion of various stakeholders. The MAC reflected this improvement, as various members noted how this process let them speak up about the potential choices to be made by transportation officials. The MIS process, as in this case, may be critiqued because it does not always lead to political "consensus". However, the MAC might have seen the success of the MIS by replacing "consensus" with "knowledge", "involvement", "participation", or "collaboration." These words emphasize the positive differences that this process has made. 


\section{REFERENCES}

Arellano, Christopher. 1997. Officials reject regional development oversight. New London Day, 16 February, B1.

Center for Conflict Resolution. 1978. A manual for group facilitation. Madison, WI: The Center for Conflict Resolution.

Connecticut Department of Transportation. 1995a. A guide for public outreach. Newington, CT: Office of Communications.

Connecticut Department of Transportation. 1995b. Managing travel in Connecticut: 100 years of progress. Newington, CT: Office of Communications.

Dilger, Robert Jay. 1992. ISTEA: A new direction for transportation planning. Publius: The Journal of Federalism. 22 (Summer): 67-78.

Emerson, Donald J. 1996. MIS successes and challenges. Conference on Major Investment Studies in transportation (MIS). No. 463 (September): 18- 23.

Florestano, Patricia S. and Laura Wilson-Gentry. 1994. The acceptability of regionalism in solving state and local problems. Spectrum: the Journal of State Government 67 (Summer): 26 (8).

Gage, Robert W. and Bruce D. McDowell. 1995. ISTEA and the role of MPOs in the new transportation environment: a midterm assessment. Publius 25 (Summer): $133-154$.

Garrett, Bruce, Connecticut Department of Transportation. 1997. Personal communication, 25 February.

Haase, Bill and Mayor Wesley J. Johnson. 1996. Letter to Connecticut Department of Transportation, Federal Highway Administration, Southeastern Connecticut Council of Governments, and Vanasse, Hangen \& Brustlin, Inc. September 18, 1996.

Innes, Judith E. 1992. Group process and the social construction of growth management. Journal of the American Planning Association 58 (Autumn): 440 - 453.

Innes, Judith E. 1996. Planning through consensus building: a new view of the comprehensive planning ideal. Journal of the American Planning Association 62 (Fall): $460-473$.

Larson, Thomas D. 1993. ISTEA: where are we after a year? Public Roads 56 (March): 135-142. 
Levin, Melvin and Norman A. Abend. 1971. Bureaucrats in collision: case studies in area transportation planning. Cambridge: The MIT Press.

Lyons, William M. 1994. FTA-FHWA metropolitan planning organization reviews: planning practice under Intermodal Surface Transportation Efficiency Act and Clean Air Act Amendments. Transportation Research Record 1466: 23-30.

Norris, Donald. 1992. Killing a COG: The death and reincarnation of the Baltimore Regional Council of Governments. Journal of Urban Affairs. 16: 155-167.

Pendergast, John. 1994. MPOs become VIPs. Civil Engineering 64 (April): 40 - 43.

Peter, Jennifer. 1997. Region appeals to state for relief from traffic congestion. New London Day, 4 March, C1, C4.

Pindur, Wolfgang and George M. Yacus. 1996. Strategic visioning for ITS regional planning: A case study for Hampton Roads, Virginia. Transportation Quarterly, 50 (Spring): 135-147.

SCCOG. 1996. Regional transportation plan for Southeastern Connecticut, FY 1997.

SCRPA. 1976. Regional plan map for southeastern Connecticut.

SCRPA. 1992. SCRPA Newsletter: September/October.

SCRPA. 1993. Annual report.

The regional planning fiction. 1997. New London Day, 20 February, A8.

U.S. Department of Transportation. 1995. A guide to metropolitan transportation planning under ISTEA: how the pieces fit together. Washington, DC: Federal Highway Administration; Federal Transit Administration. From www.bts.gov/smart/cat/424MTP.html.

USDOT, FHWA, and FTA. 1994. Innovations in public involvement for transportation planning. (January).

Vanasse Hangen Brustlin, Inc. 1994a. Proposal: scope of services, route 2/2A/32 corridor study. Submitted to Connecticut Department of Transportation. October $24,1994$.

Vanasse Hangen Brustlin, Inc. 1994b. Route 2/2A/32 MAC meeting minutes. September 1, 1994. 
Vanasse Hangen Brustlin, Inc. 1994c. Route 2/2A/32 MAC meeting minutes. November $2,1994$.

Vanasse Hangen Brustlin, Inc. 1994d. Route 2/2A/32 MAC meeting minutes. November $14,1994$.

Vanasse Hangen Brustlin, Inc. 1994e. Route 2/2A/32 MAC meeting minutes. December $7,1994$.

Vanasse Hangen Brustlin, Inc. 1994f. Route 2/2A/32 MAC meeting minutes. December $20,1994$.

Vanasse Hangen Brustlin, Inc. 1995a. Route 2/2A/32 MAC meeting minutes. February $27,1995$.

Vanasse Hangen Brustlin, Inc. 1995b. Route 2/2A/32 MAC meeting minutes. March 15, 1995.

Vanasse Hangen Brustlin, Inc. 1995c. Route 2/2A/32 MAC meeting minutes. March 27, 1995.

Vanasse Hangen Brustlin, Inc. 1995d. Route 2/2A/32 MAC meeting minutes. April 12, 1995.

Vanasse Hangen Brustlin, Inc. 1995e. Route 2/2A/32 MAC meeting minutes. April 25, 1995.

Vanasse Hangen Brustlin, Inc. 1995f. Route 2/2A/32 MAC meeting minutes. May 15, 1995.

Vanasse Hangen Brustlin, Inc. 1995g. Route 2/2A/32 MAC meeting minutes. June 6, 1995.

Vanasse Hangen Brustlin, Inc. 1995h. Route 2/2A/32 MAC meeting minutes. June 26, 1995.

Vanasse Hangen Brustlin, Inc. 1995i. Route 2/2A/32 MAC meeting minutes. July 24, 1995.

Vanasse Hangen Brustlin, Inc. 1995j. Route 2/2A/32 MAC meeting minutes. September 13, 1995.

Vanasse Hangen Brustlin, Inc. 1995k. Route 2/2A/32 MAC meeting minutes. September $28,1995$. 
Vanasse Hangen Brustlin, Inc. 19951. Route 2/2A/32 MAC meeting minutes. October $11,1995$.

Vanasse Hangen Brustlin, Inc. 1995m. Route 2/2A/32 MAC meeting minutes. November 15, 1995.

Vanasse Hangen Brustlin, Inc. 1995n. Route 2/2A/32 MAC meeting minutes. November $30,1995$.

Vanasse Hangen Brustlin, Inc. 1995o. Route 2/2A/32 MAC meeting minutes. December $13,1995$.

Vanasse Hangen Brustlin, Inc. 1995p. Route 2/2A/32 public input survey forms.

Vanasse Hangen Brustlin, Inc. 1995q. Route 2/2A/32 public meeting. January 11, 1995.

Vanasse Hangen Brustlin, Inc. 1995r. Route 2/2A/32 public meeting. January 12, 1995.

Vanasse Hangen Brustlin, Inc. 1995s. Route 2/2A/32 public meeting. July 10, 1995.

Vanasse Hangen Brustlin, Inc. 1995t. Working paper 1: route 2/2a/32 transportation study.

Vanasse Hangen Brustlin, Inc. 1996a. Route 2/2A/32 MAC meeting minutes. February 29, 1996.

Vanasse Hangen Brustlin, Inc. 1996b. Route 2/2A/32 MAC meeting minutes. March 13, 1996.

Vanasse Hangen Brustlin, Inc. 1996c. Route 2/2A/32 MAC meeting minutes. April 24, 1996.

Vanasse Hangen Brustlin, Inc. 1996d. Route 2/2A/32 MAC meeting minutes. May 7 , 1996.

Vanasse Hangen Brustlin, Inc. 1996e. Route 2/2A/32 MAC meeting minutes. May 29, 1996.

Vanasse Hangen Brustlin, Inc. 1996f. Route 2/2A/32 public meeting. January 10, 1996.

Vanasse Hangen Brustlin, Inc. 1996g. Route 2/2A/32 public meeting. March 18, 1996.

Vanasse Hangen Brustlin, Inc. 1997. Route 2/2A/32 transportation study. Major Investment Study. Final report. 
Wallis, Allan D. 1994. Inventing regionalism: a two-phase approach. National Civic Review 83: 447 (22).

Weiner, Edward. 1992. History of urban transportation planning. Editors George E. Gray and Lester A. Hoel. Public Transportation, Second Edition. Englewood Cliffs, New Jersey: Prentice Hall. 